\title{
Substituent effects on the gas-phase fragmentation reactions of protonated peptides containing benzylamine-derivatized lysyl residues
}

\author{
E. S. Simon*, P. G. Papoulias and P. C. Andrews \\ Departments of Biological Chemistry, Bioinformatics, and Chemistry, University of Michigan, Ann Arbor, MI 48103, USA
}

Motivated by the need for chemical strategies designed to tune peptide fragmentation to selective cleavage reactions, benzyl ring substituent influence on the relative formation of carbocation elimination (CCE) products from peptides with benzylamine-derivatized lysyl residues has been examined using collision-induced dissociation (CID) tandem mass spectrometry. Unsubstituted benzylamine-derivatized peptides yield a mixture of products derived from amide backbone cleavage and CCE. The latter involves side-chain cleavage of the derivatized lysyl residue to form a benzylic carbocation $\left[\mathrm{C}_{7} \mathrm{H}_{7}\right]^{+}$and an intact peptide product ion $\left[\left(\mathrm{MH}_{\mathrm{n}}\right)^{\mathrm{n}+}-\left(\mathrm{C}_{7} \mathrm{H}_{7}\right)^{+}\right]^{(\mathrm{n}-1)+}$. The CCE pathway is contingent upon protonation of the secondary $\varepsilon$-amino group $\left(\mathrm{N}_{\varepsilon}\right)$ of the derivatized lysyl residue. Using the Hammett methodology to evaluate the electronic contributions of benzyl ring substituents on chemical reactivity, a direct correlation was observed between changes in the CCE product ion intensity ratios (relative to backbone fragmentation) and the Hammett substituent constants, $\sigma$, of the corresponding substituents. There was no correlation between the substituent-influenced gas-phase proton affinity of $N_{\varepsilon}$ and the relative ratios of CCE product ions. However, a strong correlation was observed between the $\pi$ orbital interaction energies $\left(\Delta E_{\mathrm{int}}\right)$ of the eliminated benzylic carbocation and the logarithm of the relative ratios, indicating the predominant factor in the CCE pathway is the substituent effect on the level of hyperconjugation and resonance stability of the eliminated benzylic carbocation. This work effectively demonstrates the applicability of $\sigma$ (and $\Delta E_{\text {int }}$ ) as substituent selection parameters for the design of benzylbased peptide-reactive reagents which tune CCE product formation as desired for specific applications. Copyright $(\subset)$ 2012 John Wiley \& Sons, Ltd.

Protonated peptides dissociate primarily along the amide backbone when analyzed under the low-energy regime of collision-induced dissociation (CID) tandem mass spectrometry (MS/MS). ${ }^{[1]}$ Knowledge of this fragmentation characteristic has been applied indispensably in the field of proteomics for comparing MS/MS spectral data of peptides against in silico peak lists generated from large genome databases. ${ }^{[2-4]} \mathrm{How}^{-}$ ever, it has been recognized that other applications of CID-MS/MS to protonated peptide analysis can benefit from selective side-chain or selective amide backbone cleavage reactions. For multiple-reaction monitoring (MRM), it has been demonstrated that chemical modifications which induce the selective cleavage of an amide bond concentrates the total product ion current (normally diluted among several product ions) into two charged fragments. ${ }^{[5]}$ The selection of these two exclusive fragments as MRM transitions increases the sensitivity of the assay by up to two orders of magnitude. It has also been demonstrated that employing cross-linking reagents which promote selective side-chain cleavage along the linker moiety of cross-linked peptides allows for the two linked peptides to dissociate as intact protonated peptide

* Correspondence to: E. S. Simon, 3561 Lexington Circle, Dexter, MI 48130, USA.

E-mail: eric.simon@nextgensciences.com product ions which can be independently interrogated in subsequent tandem MS scans. ${ }^{[6,7]}$ This circumvents the tedious interpretation of ambiguous MS/MS spectra that are characteristic of cross-linked peptides (linked with conventional crosslinking reagents) which exhibit overlapping amide cleavage products from the two linked peptides if they fragment at all.

Since these applications demonstrate the increasing demand for chemical strategies that promote selective fragmentation of derivatized peptides, we have recently begun evaluating the chemical incorporation of benzylamine derivatives to assess their effectiveness in manipulating CID of protonated peptides. ${ }^{[8]} \mathrm{N}$-Alkyl-N-benzylammonium ions fragment via CID to form a benzylic carbocation $\left[\mathrm{C}_{7} \mathrm{H}_{7}\right]^{+}$and neutral amine. ${ }^{[9,10]}$ This pathway has been studied extensively in the associated benzylpyridinium cations which have been applied as 'thermometer ions' for determining the internal energy distribution of ions generated from soft ionization techniques as described in a recent review. ${ }^{[11]}$ Our recent work showed that this reaction is preserved in peptides containing $\varepsilon$-benzyl-lysyl residues (incorporated via reductive benzyl-amination) contingent that the secondary $\varepsilon$-amino group $\left(\mathrm{N}_{\varepsilon}\right)$ of the benzyl-aminated lysyl residue is protonated. ${ }^{[8]}$ This has been termed the carbocation elimination (CCE) pathway (Scheme 1). For precursor ions not protonated at $\mathrm{N}_{\varepsilon}$ of the lysyl residues, amide backbone cleavage reactions persist. Therefore, at lower precursor ion charge states, a mixture of amide cleavage and CCE products were observed. 

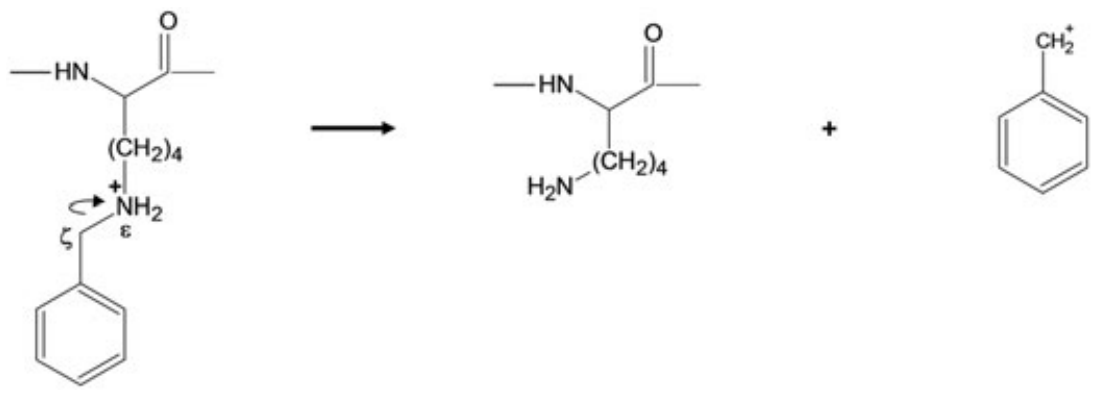

Scheme 1. The carbocation elimination (CCE) pathway.

As the charge state of the precursor increased to the point of saturating all favorable sites of protonation, the products of the CCE pathway were formed almost exclusively.

It was concluded from these results that the incorporation of suitable substituents with appropriate electronic properties onto the benzyl ring of the benzylamine derivatives would allow modulation of the relative yield of CCE products to suit a desired application. Substituents with distinct electron-donating or electron-withdrawing capabilities could influence the gas-phase proton affinity of $\mathrm{N}_{\varepsilon}$ and/or the thermodynamic stability of the incipient benzylic carbocation; both of which may be contributing factors involved in the observed yield of CCE product ions. Evaluating the effects of various substituents on the yield of CCE product ions would provide a foundation for rational and versatile design strategy for reagents that induce fragmentation patterns to suit specific applications (e.g. cross-linking reagents, stable-isotope quantification tags, etc.). Additionally, complimentary properties may be incorporated (e.g. a substituent that induces the formation of desired product ion ratios or introduction of an affinity handle for enriching targeted peptide subsets from complex mixtures).

The specific goal of this work was to demonstrate the substituent-induced manipulation of the relative abundance of CCE product ions formed via CID-MS/MS of a model peptide chemically modified with various ring-substituted benzylamine derivatives. This is part of a long-term goal to develop benzyl derivatization reagents that promote selective CCE reactivity regardless of the precursor ion charge state which is a desirable characteristic of reagents used in applications like protein cross-linking. In this work, the ratio, $R_{X}$, of the sum of the CCE product ion intensities to the sum of the total remaining product ion current was determined for each of the substituted benzylamine derivatives of the model peptide for comparison against the ratio, $R_{\mathrm{H}}$, of the unsubstituted derivative. Using the empirically derived Hammett substituent methodology ${ }^{[12,13]}$ which estimates the electronic effects of substituents on chemical reactions, a strong linear correlation was observed between the $\log \left(R_{\mathrm{X}} / R_{\mathrm{H}}\right)$ and the corresponding Hammett substituent constants, $\sigma$. This demonstrates $\sigma$ as a suitable substituent selection parameter for the design of peptide-reactive reagents to manipulate fragmentation mechanisms. Also presented here is evidence that the observed ratios are dependent on the substituent influence on the thermodynamic stability of the eliminated benzylic carbocation rather than the substituent influence on the gas-phase proton affinity of $\mathrm{N}_{\varepsilon}$.

\section{EXPERIMENTAL}

\section{Materials}

Unless otherwise stated, all reagents were purchased from Sigma-Aldrich (St. Louis, MO, USA). The N-terminally acetylated peptide (Ac-RIGKGVAR) used in this study was synthesized by the Protein Structure Facility, part of the Biomedical Research Core Facilities, at the University of Michigan Medical School (Ann Arbor, MI, USA).

\section{Preparation of a benzylamine-derivatized tryptic peptide and substituted analogs}

Peptides $(5 \mu \mathrm{g})$ were dissolved in $100 \mu \mathrm{L}$ of $100 \mathrm{mM}$ triethylammonium bicarbonate (TEAB, $\mathrm{pH} \sim 8.5$ ) containing 25 to $50 \%$ methanol and $\sim 30 \mathrm{mmol}$ of benzaldehyde or substituted analog. The Schiff bases formed between the aldehydes and the primary amino groups on the peptides were reduced to secondary amines by adding $5 \mu \mathrm{L}$ of $1 \mathrm{M}$ sodium borohydride. The reduction reaction was allowed to proceed undisturbed at room temperature for $45 \mathrm{~min}$ in a fume hood in the dark. The reaction was quenched by adding $1 \mathrm{~mL}$ of $0.1 \%$ trifluoroacetic acid. The reacted peptides were desalted using a Strata- $X$ reversed-phase C18 cartridge (Phenomenex, Torrance, CA, USA) according to the manufacturer's instructions. The desalted peptides were dried and redissolved in $200 \mu \mathrm{L}$ of $100 \mathrm{mM}$ TEAB (pH 8.5). L-(Tosylamido-2-phenyl)ethylchloromethyl ketone-treated trypsin $(1 \mu \mathrm{g})$, obtained from Worthington Biochemical Corp. (Lakewood, NJ, USA), was added to the peptide solution and incubated at $37^{\circ} \mathrm{C}$ overnight. The digested peptides were desalted as described above, dried to completion, and redissolved in $50 \mu \mathrm{L}$ of $25 \%$ acetonitrile/ $0.1 \%$ formic acid $(\mathrm{v} / \mathrm{v})$ for analysis with nanospray ionization tandem mass spectrometry.

\section{Mass spectrometry}

Peptides were analyzed with a model LTQ-Orbitrap XL hybrid linear quadrupole ion trap-orbitrap mass spectrometer (ThermoFisher Scientific, Inc., San Jose, CA, USA). They were introduced by infusion using a TriVersa Nanomate nanospray ionization source (Advion BioSciences, Ithaca, NY, USA). Peptides were delivered with a pneumatic displacement pressure of 0.45 psi and an applied spray voltage of $1.54 \mathrm{kV}$. The heated capillary temperature was set at $200{ }^{\circ} \mathrm{C}$. Monoisotopic precursor ions were selected for multi-stage tandem mass spectrometric acquisition 
using an isolation window of $3.0 \mathrm{~m} / \mathrm{z}$ units and excitation energy settings of 35 for MS/MS spectra. All MS/MS spectra were collected in FT (Orbitrap) mode for high mass accuracy $(>10 \mathrm{ppm})$ and peak resolution (15 000 at $\mathrm{m} / \mathrm{z} 400)$. Automatic gain control was maintained at 500 000 for precursor ion scans and 100000 for product ion scans to ensure a comparable count of precursor and product ions transmitted to the orbitrap analyzer for all of the derivatized peptides analyzed.

\section{Data processing and analysis}

Product ion spectra were analyzed in peak list format. Peak lists were extracted using the Qualbrowser package from the mass spectrometer operating software Excalibur version 2.0.7 (ThermoFisher Scientific, Inc., San Jose, CA, USA). To minimize noise contributions to the summed product ion intensities, peaks with less than $1.0 \%$ of the relative intensity (R.I.) of the base peak were not used. Exceptions to keeping peaks that were less than $1.0 \%$ R.I. were limited to those representing CCE product ions whose $\mathrm{m} / \mathrm{z}$ value matched the theoretical $\mathrm{m} / \mathrm{z}$ value at better than $10 \mathrm{ppm}$. Product ion intensity ratios for substituted peptide derivatives, $R_{X}$, were determined for comparison against the unsubstituted derivative, $R_{\mathrm{H}}$. The ratios were defined as $R_{\mathrm{X}}=\Sigma\left(I_{\mathrm{CCE}}\right) / \Sigma\left(I_{\text {total }}\right.$ - $\left.I_{\mathrm{CCE}}\right)$ where $I_{\mathrm{CCE}}$ and $I_{\text {total }}$ represent the CCE and total product ion current, respectively.

\section{Computational methods}

$N$-Benzyl-N-butylamine and substituted analogs were used as models to represent the structure of the derivatized lysyl side chains for calculating and comparing the substituent effects on the gas-phase proton affinity of the secondary $\varepsilon$-amino group. Low-energy conformations for the neutral and corresponding protonated structures were determined and optimized at the B3LYP level of theory using the 6-31 $G+(d, p)$ basis set. For each structure, several starting configurations were created using chemical intuition and optimized (see Supplementary Figs. S3 and S4, Supporting Information). The lowest energy structures were subjected to harmonic vibrational frequency analysis and visualized using the software package GaussView 3.0. All calculations where done using the Gaussian 2003 molecular modeling software package. ${ }^{[14]}$

\section{RESULTS}

\section{CID tandem mass spectra of benzylamine and substituted benzylamine lysyl-derivatized peptides}

Figure 1 displays CID product ion spectra of a representative model peptide IGK $\mathrm{X}$ GVAR (where X represents the substituent on the benzyl ring of the modified lysyl residue). Figures $1(\mathrm{~A})$ and 1(B) display MS/MS spectra of the doubly and triply charged precursor ions of the unsubstituted benzylamine analog IGK $_{\mathrm{H}} \mathrm{GVAR}$, respectively. Consistent with benzylaminated peptides examined in our previous study, ${ }^{[8]}$ IGK $_{\mathrm{H}}$ GVAR yields products from two main pathways: the $b_{m}-y_{n}$ pathway ${ }^{[15,16]}$ which produces a mixture of sequence ions and the CCE pathway which produces a benzylic carbocation $\left[\mathrm{C}_{7} \mathrm{H}_{7}\right]^{+}$and a peptide product ion
$\left[\left(\mathrm{MH}_{\mathrm{n}}\right)^{\mathrm{n}+}-\left(\mathrm{C}_{7} \mathrm{H}_{7}\right)^{+}\right]^{(\mathrm{n}-1)+}$. Typical of ion trap mass spectrometers, the omission of low $\mathrm{m} / \mathrm{z}$ product ions in tandem mass spectral scans precluded the detection of the carbocations formed from doubly charged precursor ions. To demonstrate that doubly charged precursors do form a benzylic carbocation upon activation, higher energy collisionally activated dissociation (HCD) $)^{[17]}$ was used to acquire a complimentary MS/MS spectrum of the doubly charged precursor of $\mathrm{IGK}_{\mathrm{H}} \mathrm{GVAR}$ (Supplementary Fig. S1, Supporting Information). HCD permits the detection of low $\mathrm{m} / \mathrm{z}$ product ions and the spectrum exhibits a peak representing the presence of the benzylic carbocation at $\mathrm{m} / \mathrm{z}$ 91. The MS/MS spectrum of the triply charged precursor ion of IGK $\mathrm{H}_{\mathrm{H}} \mathrm{GAR}$ displays an intense peak representing a $\mathrm{y}_{6}{ }^{2+}$ product ion in addition to peaks representing CCE products (Fig. 1(B)). This is a unique fragmentation feature among other triply charged benzyl-aminated peptides examined which typically yield CCE products almost exclusively. The observation of an amide cleavage product at such unusually high abundance from a benzylamine-substituted peptide in the triply charged state afforded us a rare opportunity to assess the substituent effects on the relative formation of product ions generated from the CCE pathway from both doubly and triply charged precursors in this study.

Figure 1 also includes spectra from two substituted benzylamine derivatives of the model peptide. Figures 1(C) and 1(D) display MS/MS spectra of the doubly and triply charged precursors of the $m-\mathrm{CH}_{3}$ derivative (IGK ${ }_{m \mathrm{CH}} \mathrm{GVAR}$ ) and Figs. 1(E) and 1(F) display MS/MS spectra of the doubly and triply charged precursors of the $m$-F derivative $\left(\mathrm{IGK}_{m \mathrm{~F}} \mathrm{GVAR}\right)$, respectively. Comparing the spectra of the three derivatives in Fig. 1, CCE product ion intensities are enhanced for the $m-\mathrm{CH}_{3}$ derivative (represented by $\left[\left(\mathrm{MH}_{2}\right)^{2+}-\left[\mathrm{C}_{8} \mathrm{H}_{9}\right]^{+}\right]^{+}$in Fig. $1(\mathrm{C})$ and both $\left[\mathrm{C}_{8} \mathrm{H}_{9}\right]^{+}$and $\left[\left(\mathrm{MH}_{3}\right)^{3+}-\left[\mathrm{C}_{8} \mathrm{H}_{9}\right]^{+}\right]^{2+}$ in Fig. 1(D)) and reduced for the $m-\mathrm{F}$ derivative (represented by $\left[\left(\mathrm{MH}_{2}\right)^{2+}-\left[\mathrm{C}_{7} \mathrm{H}_{6} \mathrm{~F}_{1}\right]^{+}\right]^{+}$in Fig. 1(E) and both $\left[\mathrm{C}_{7} \mathrm{H}_{6} \mathrm{~F}_{1}\right]^{+}$and $\left[\left(\mathrm{MH}_{3}\right)^{3+}-\left[\mathrm{C}_{7} \mathrm{H}_{6} \mathrm{~F}_{1}\right]^{+}\right]^{2+}$ in Fig. 1(F)) relative to the corresponding peaks for the unsubstituted derivative (Figs. 1(A) and 1(B)). These spectra illustrate the general trend of the influence of benzylaminesubstituted derivatives of $\mathrm{IGK}_{\mathrm{X}} \mathrm{GVAR}$ on the ratio of CCE to $b_{m}-y_{n}$ product ion intensities observed in the MS/MS spectra. Electron-donating substitutents, e.g., methyl groups, increase the relative abundance of CCE product ions while electron-withdrawing substitutents like fluorine decrease the relative abundance of CCE product ions.

Table 1 lists the product ion intensity ratios, $R_{X}$, for each $X$-substituted benzylamine derivative of the model peptide analyzed via CID-MS/MS along with the Hammett substituent constant, $\sigma$, for each substituent obtained from the literature. ${ }^{[13]}$ For this study, $R_{X}$ is defined as the sum of the CCE product ion intensities, $I_{\mathrm{CCE}}$, for the $\mathrm{X}$-substituted derivative over the sum of the remaining product ion intensities (i.e. $R_{\mathrm{X}}=\Sigma\left(I_{\mathrm{CCE}}\right) / \Sigma\left(I_{\text {total }}-I_{\mathrm{CCE}}\right) . R_{\mathrm{H}}$ represents the corresponding ratio for the unsubstituted derivative. For doubly charged precursors, $I_{\mathrm{CCE}}$ was composed solely of the intensity of the $\left[\left(\mathrm{MH}_{2}\right)^{2+}-\left(\mathrm{C}_{7} \mathrm{H}_{7}\right)^{+}\right]^{+}$product ion since the $\mathrm{m} / \mathrm{z}$ values for the associated carbocations were too low for detection. The meta- and para-Hammett substituent constants, $\sigma_{m}$ and $\sigma_{p}$, have long been used to describe an empirical relationship between the electronic properties (i.e. electron-withdrawing 


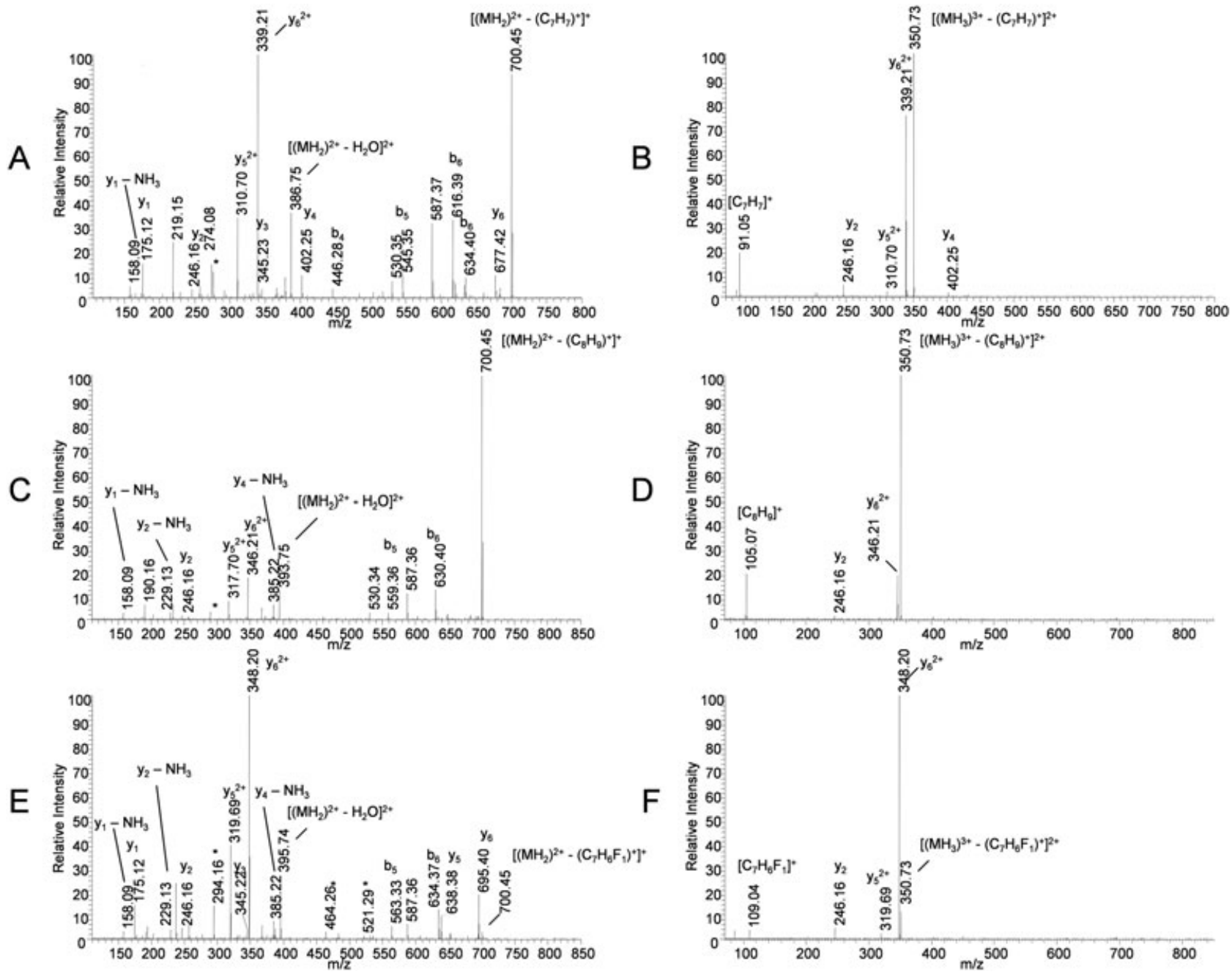

Figure 1. CID MS/MS product ion spectra of the doubly and triply protonated, $\left[\mathrm{MH}_{\mathrm{n}}\right]^{\mathrm{n}+}(\mathrm{n}=2$ or 3$)$, peptide IGK $\mathrm{GVAR}$ where $K_{X}$ represents a substituted benzylamine-derivatized lysyl residue: $(\mathrm{A})\left[\mathrm{MH}_{2}\right]^{2+}, \mathrm{X}=\mathrm{H} ;(\mathrm{B})[\mathrm{MH}]^{3+}, \mathrm{X}=\mathrm{H}$; (C) $\left[\mathrm{MH}_{2}\right]^{2+}, \mathrm{X}=m-\mathrm{CH}_{3} ;(\mathrm{D})\left[\mathrm{MH}_{3}\right]^{3+}, \mathrm{X}=m-\mathrm{CH}_{3} ;(\mathrm{E})\left[\mathrm{MH}_{2}\right]^{2+}, \mathrm{X}=m-\mathrm{F}$; and (F) $\left[\mathrm{MH}_{3}\right]^{3+}, \mathrm{X}=m-\mathrm{F}$.

or -donating properties through field/inductive or resonance effects) of a substituent and the thermodynamics and kinetics of a chemical reaction as described by the Hammett equation $^{[18]}$ (Eqn. (1):

$$
\log \left(k_{\mathrm{X}} / k_{\mathrm{H}}\right)=\rho \sigma
$$

where $k_{\mathrm{X}}$ represents a rate or equilibrium constant from an X-substituted reactant, $k_{\mathrm{H}}$ represents the corresponding unsubstituted reactant, and the reaction constant $\rho$ represents the sensitivity of the substituent effect on the reaction. Since the goal here was to assess the effects of various substituents on $R_{\mathrm{X}}$ relative to $R_{\mathrm{H}}$, we adopted an alternative form of the Hammett equation, Eqn. (2):

$$
\log \left(R_{\mathrm{X}} / R_{\mathrm{H}}\right)=\rho \sigma
$$

This describes the relationship of the substituent on the balance between the CCE fragmentation pathway and the $\mathrm{b}_{\mathrm{m}}-\mathrm{y}_{\mathrm{n}}$ pathway. Figure 2(A) displays a plot of $\log \left(R_{\mathrm{X}} / R_{\mathrm{H}}\right)$ versus $\sigma$ for doubly charged precursors and the corresponding plot for the triply charged precursors is displayed in
Fig. 2(B). Equation (2) provides an effective description of the correlation between the electronic properties of the various substituents and the observed product ion intensity ratios. Generally, the plots in Fig. 2 show that electron-donating substituents facilitate enhanced CCE product formation while electron-withdrawing substituents effectively reduce CCE product formation. Derivatives with substituents having $\sigma$ constants above 0.5 exhibit CCE product ion peaks of very low relative intensity or no peaks at all. For doubly charged precursors, no evidence for CCE products was observed for the $m-\mathrm{CN}\left(\sigma_{\mathrm{m}}=0.56\right)$ and $p-\mathrm{NO}_{2}\left(\sigma_{\mathrm{p}}=0.78\right)$ derivatives. On the other hand, derivatives with substituents having $\sigma$ constants below -0.20 exhibit selective CCE product ion formation. For the $p-\mathrm{OCH}_{3}\left(\sigma_{\mathrm{p}}=-0.27\right)$ and $p-\mathrm{OH}\left(\sigma_{\mathrm{p}}=-0.37\right)$ derivatives, the respective $\mathrm{C}_{\zeta}-\mathrm{N}_{\varepsilon}$ bonds were so labile that the precursor ions dissociated in the ion trap before activation as evident by intense peaks representing the $p-\mathrm{OCH}_{3}$ and $p-\mathrm{OH}$ carbocations in their corresponding precursor ion spectra (data not shown). Overall, Fig. 2 illustrates the feasibility for applying Hammett constants as effective prediction parameters for substituent selection to modulate CCE product ion formation as desired for specific applications. 
Table 1. List of substituents examined on the benzylamine-derivatized model peptide along with corresponding Hammett substituent constants, experimentally determined product ion intensity ratios $\left(R_{\mathrm{X}}\right)$, and calculated logarithm of the relative intensity ratios, $\log \left(R_{\mathrm{X}} / R_{\mathrm{H}}\right)$

\begin{tabular}{|c|c|c|c|c|c|}
\hline \multirow[b]{2}{*}{ Substituent } & \multirow[b]{2}{*}{$\sigma^{\mathrm{a}}$} & \multicolumn{2}{|c|}{$2 \pm$ Precursors } & \multicolumn{2}{|c|}{$3 \pm$ Precursors } \\
\hline & & $R_{\mathrm{X}}$ & $\log \left(R_{\mathrm{X}} / R_{\mathrm{H}}\right)^{\mathrm{b}}$ & $R_{\mathrm{X}}$ & $\log \left(R_{\mathrm{X}} / R_{\mathrm{H}}\right)^{\mathrm{c}}$ \\
\hline$p-\mathrm{CH}_{3}$ & -0.17 & 20.04 & 1.92 & 106.99 & 1.90 \\
\hline$m-\mathrm{CH}_{3}$ & -0.07 & 1.03 & 0.63 & 5.51 & 0.61 \\
\hline$p-\mathrm{F}$ & 0.06 & 0.59 & 0.39 & 10.79 & 0.90 \\
\hline$m-\mathrm{OH}$ & 0.12 & 0.19 & -0.096 & 0.94 & -0.16 \\
\hline$m-\mathrm{F}$ & 0.34 & 0.0087 & -1.44 & 0.12 & -1.05 \\
\hline$m-\mathrm{CN}$ & 0.56 & 0 & - & 0.0033 & -2.61 \\
\hline$p-\mathrm{CN}$ & 0.66 & 0.00064 & -2.57 & 0.015 & -1.94 \\
\hline$p-\mathrm{NO}_{2}$ & 0.78 & 0 & - & 0.00079 & -3.24 \\
\hline$m-\mathrm{Cl}$ & 0.37 & 0.014 & -1.23 & 0.19 & -0.86 \\
\hline$p-\mathrm{Cl}$ & 0.23 & 0.43 & 0.26 & 0.26 & -0.72 \\
\hline$m-\mathrm{OCH}_{3}$ & 0.12 & 0.72 & 0.48 & 3.89 & 0.46 \\
\hline$o-\mathrm{CH}_{3}$ & - & 4.76 & 1.30 & 33.66 & 1.40 \\
\hline$o-\mathrm{F}$ & - & 0.045 & -0.72 & 0.26 & -0.72 \\
\hline
\end{tabular}
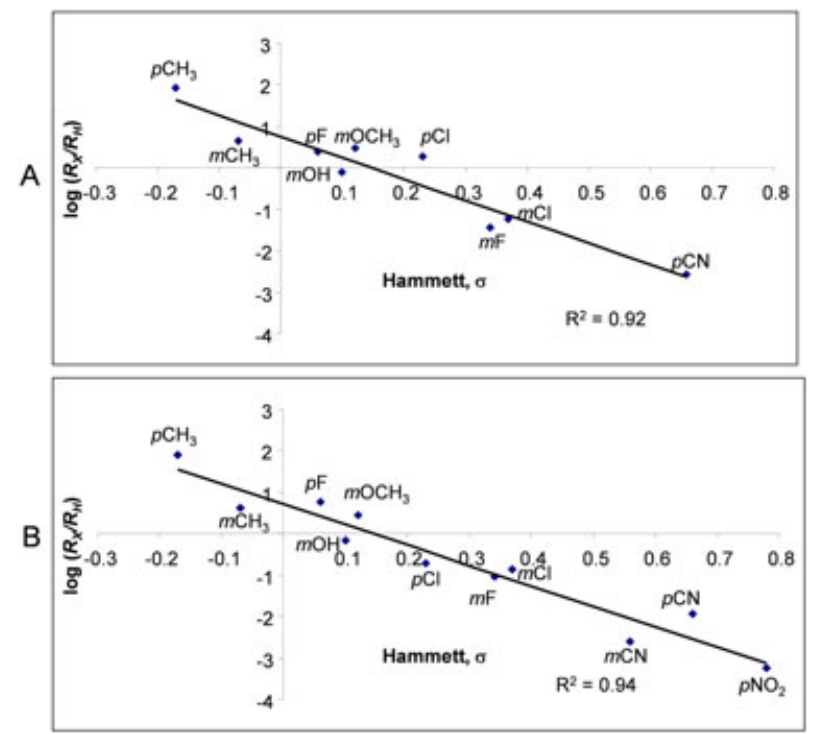

Figure 2. Plot of $\log \left(R_{\mathrm{X}} / R_{\mathrm{H}}\right)$ versus Hammett substituent constant, $\sigma$, for various substituents $(\mathrm{X})$ on the benzylaminederivatized doubly (A) and triply (B) protonated peptide IGK ${ }_{X}$ GVAR. $R_{X}$ represents the sum of the CCE product ion intensities of an $X$-substituted derivative over the sum of the remainder of the product ion intensities. $R_{\mathrm{H}}$ represents the corresponding ratio of the unsubstituted derivative.

\section{Electronic influence of substituents on the observed product ion ratios}

The influence of substituent electronic effects on the observed product ion ratios could potentially result from the substituents' influence on the gas-phase proton affinity (PA) of $\mathrm{N}_{\varepsilon}$ of the derivatized lysyl residue. For example, an electrondonating substituent might be expected to increase the PA of $\mathrm{N}_{\varepsilon}$, resulting in a greater proportion of precursor ions protonated at $\mathrm{N}_{\varepsilon}$. Since the CCE dissociation pathway is contingent upon protonation of $\mathrm{N}_{\varepsilon}$, then increasing the population of precursor ions protonated at $\mathrm{N}_{\varepsilon}$ could conceivably produce a higher yield of CCE products. An alternative or contributing factor could be the substituents' influence on the thermodynamic stability of the departing benzylic carbocation. This latter effect would apply if formation of the carbocation were the rate-limiting step in the CCE pathway.

$N$-Benzyl- $N$-butylamine was applied as a model structure for estimating the relative influence of ring substitutions on the gas-phase PA of $\mathrm{N}_{\varepsilon}$ of benzylamine-derivatized lysyl side chains using B3LYP/6-31 + G(d,p) density functional theory. There was no obvious correlation exhibited between the observed product ion intensity ratios and the estimated PAs (Supplementary Table S1, Supporting Information). To further illustrate this point as well as to facilitate discussion later, the CID product ion spectra for the doubly charged precursor ions of the $o-\mathrm{CH}_{3}, m-\mathrm{CH}_{3}$, and $p-\mathrm{CH}_{3}$ derivatives of the model peptide are displayed in Figs. 3(A)-3(C), respectively. Although the position of methylation has minimal influence on the gas-phase PA of $\mathrm{N}_{\varepsilon}$ (231.2, 232.2, and $232.6 \mathrm{kcal} / \mathrm{mol}$, respectively), it has a substantial influence on the relative formation of CCE product ions $\left(\mathrm{R}_{o \mathrm{CH}}=4.76\right.$, $\mathrm{R}_{m \mathrm{CH} 3}=1.03$, and $\mathrm{R}_{p \mathrm{CH} 3}=20.0$, respectively).

However, the product ion intensity ratios do correlate strongly with the relative thermodynamic stabilities of the methylated benzylic carbocations. A previous study used energy decomposition analysis (EDA) $)^{[19]}$ to examine the interaction energies, $\Delta E_{\text {int }}$, associated with several substituted benzylic carbocations. ${ }^{[20]}$ Essentially, $\Delta E_{\text {int }}$ represents the sum of the attractive and repulsive components of the $\pi$ orbital interactions (including conjugation and hyperconjugation) between the ${ }^{+} \mathrm{CH}_{2}$ and $\mathrm{C}_{6} \mathrm{H}_{4} \mathrm{X}$ fragments of the benzylic carbocations. This allows for the estimation and comparison of the substituent effects on the relative thermodynamic stability through resonance delocalization of the positive charge of the various substituted benzylic carbocations. The relative stability of the methylated benzylic carbocations (based on the EDA-determined $\Delta E_{\text {int }}$ values) is $p-\mathrm{CH}_{3}>0-\mathrm{CH}_{3}>$ $m-\mathrm{CH}_{3}$ which reflects the relative propensity of the respective 


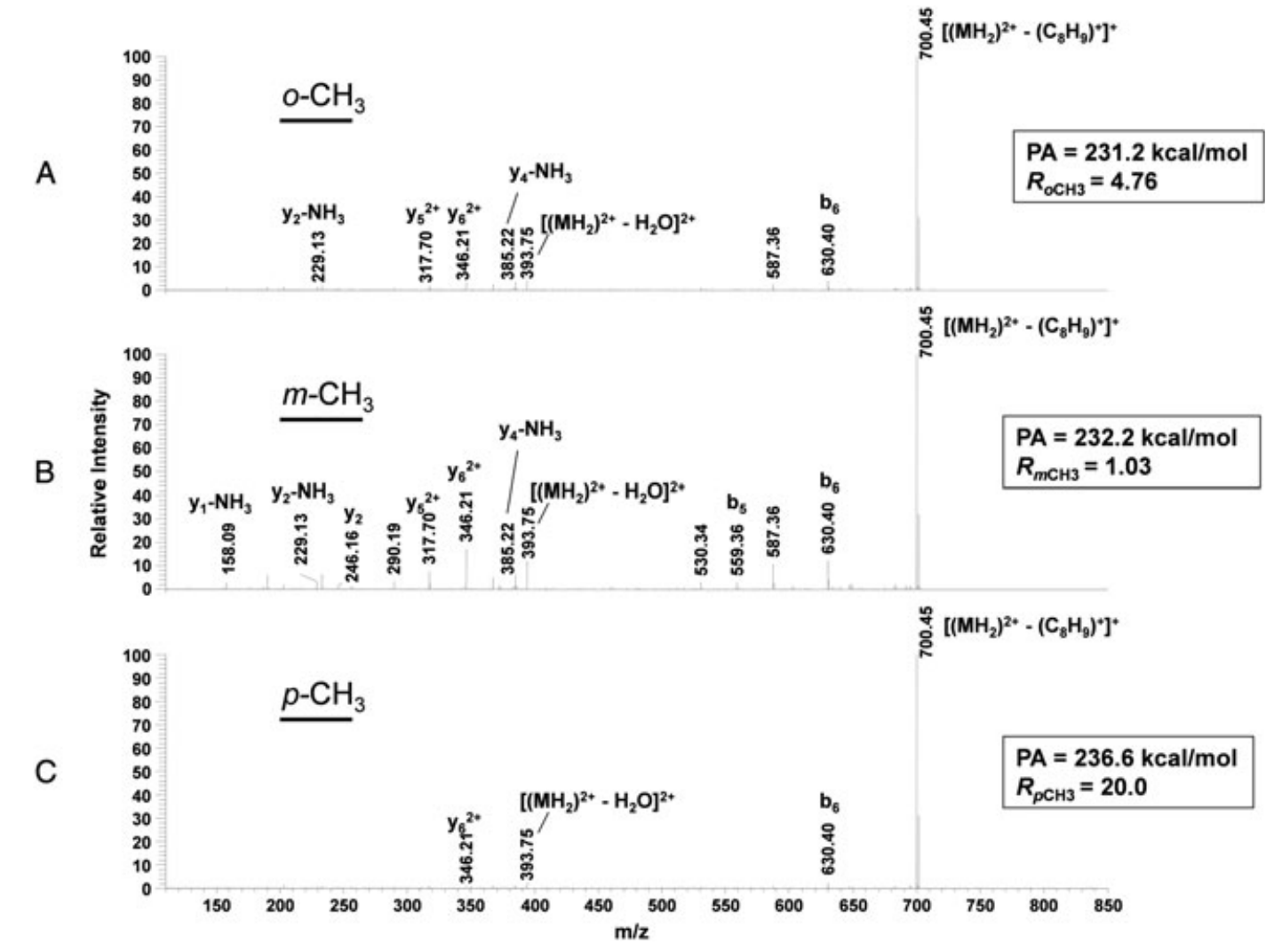

$\left[\left(\mathrm{MH}_{2}\right)^{2 *}-\left(\mathrm{C}_{8} \mathrm{H}_{9}\right)\right]^{*}$

Figure 3. CID MS/MS product ion spectra of the doubly protonated $\left[\mathrm{MH}_{2}\right]^{2+}$ precursor ions of three methylated analogs of IGK $\mathrm{X}$ GVAR: (A) $\mathrm{X}=0-\mathrm{CH}_{3}$; (B) $\mathrm{X}=m-\mathrm{CH}_{3}$; and (C) $\mathrm{X}=p-\mathrm{CH}_{3}$. Corresponding insets display estimated gas-phase proton affinities (PA) of the corresponding secondary $\varepsilon$-amino groups of the derivatized lysyl side chains and the corresponding product ion intensity ratios, $R_{\mathrm{X}}$.

methylated derivatives for fragmenting via the CCE pathway, $\left(R_{p \mathrm{CH} 3}>R_{o \mathrm{CH} 3}>R_{m \mathrm{CH} 3}\right)$. Figures $4(\mathrm{~A})$ and $4(\mathrm{~B})$ display plots of $\log \left(R_{\mathrm{X}} / R_{\mathrm{H}}\right)$ from doubly and triply charged precursors of the examined substituted derivatives of the model peptide respectively versus the EDA-determined $\Delta E_{\text {int }}$ values for several meta- and para-X-substituted benzylic carbocations. A strong linear correlation is observed for both charge states indicating a direct relationship between the level of $C_{\zeta}-N_{\varepsilon}$ bond cleavage (and therefore the measurement of $R_{\mathrm{X}}$ ) and the $\pi$ orbital interaction between the fragments ${ }^{+} \mathrm{CH}_{2}$ and $\mathrm{C}_{6} \mathrm{H}_{4} \mathrm{X}$ of the eliminated benzylic carbocation. In other words, the substituent influence on the stability of the developing benzylic carbocation (upon CID activation) appears to be the prevailing factor in determining the relative abundance of CCE product ion formation. Electron-donating groups make the carbocation a better leaving group while electron-withdrawing groups have the opposing effect. For the peptide IGK $x$ GVAR, a substituent-induced $\Delta E_{\text {int }}$ value of approximately $-230 \mathrm{kcal} /$ mol is indicative of substituent-induced stabilization of the incipient benzylic carbocation thus facilitating the predominant formation of CCE products. A $\Delta E_{\text {int }}$ value of approximately $-210 \mathrm{kcal} / \mathrm{mol}$ is indicative of destabilization of the incipient benzylic carbocation and thus effective abortion of the CCE pathway and an almost complete absence of CCE products.

Considering that Hammett substituent constants are not available for the ortho position and the remarkable correlation between $\Delta E_{\text {int }}$ and the logarithm of the observed product ion intensity ratios of meta- and para-substituted derivatives, we selected two ortho-substituted analogs $\left(o-\mathrm{CH}_{3}\right.$ and $\left.o-\mathrm{F}\right)$ of the model peptide to determine if $\Delta E_{\text {int }}$ can be applied to estimate the relative formation of CCE products at the ortho position as well. The rationale for selecting the analogs $o-\mathrm{CH}_{3}$ and $o-\mathrm{F}$ was drawn from their EDA-determined $\Delta E_{\text {int }}$ values ( -224.9 and $-221.0 \mathrm{kcal} / \mathrm{mol}$, respectively) which fall within the range of -230 to $-210 \mathrm{kcal} / \mathrm{mol}$ where CCE products ions were observed among a mixture of other products from the meta- and para-derivatives. Figures $4(\mathrm{C})$ and 4(D) display the corresponding plots from Figs. 4(A) and 4(B) for the doubly and triply charged derivatized analogs respectively with inclusion of the $o-\mathrm{CH}_{3}$ and $o-\mathrm{F}$ data points. A strong correlation persists between $\log \left(R_{X} / R_{\mathrm{H}}\right)$ and $\Delta E_{\text {int }}$ although the $0-\mathrm{F}$ data point reduces the linear correlations to 0.95 and 0.96 , respectively. The linear correlation remains above 0.99 for both plots if only the $o-\mathrm{CH}_{3}$ data is included. The slight deviation of the $o$-F data point from the rest of the dataset may be due to steric effects or other secondary interactions (e.g. electrostatic, hydrogen bonding, etc.). Such interactions are more common for ortho substitutions, which is why Hammett substituent constants have been omitted for the ortho position, ${ }^{[21]}$ and may be more problematic in peptide applications where strong interactions with the amide backbone and other amino acid side chains are more likely at the ortho position. Our group recently observed such an example where derivatization with the $o-\mathrm{OH}$ analog introduced an alternate and complimentary dissociation pathway to CCE which cleaves the $\mathrm{C}_{\zeta}-\mathrm{N}_{\varepsilon}$ bond via a retro-Michael 

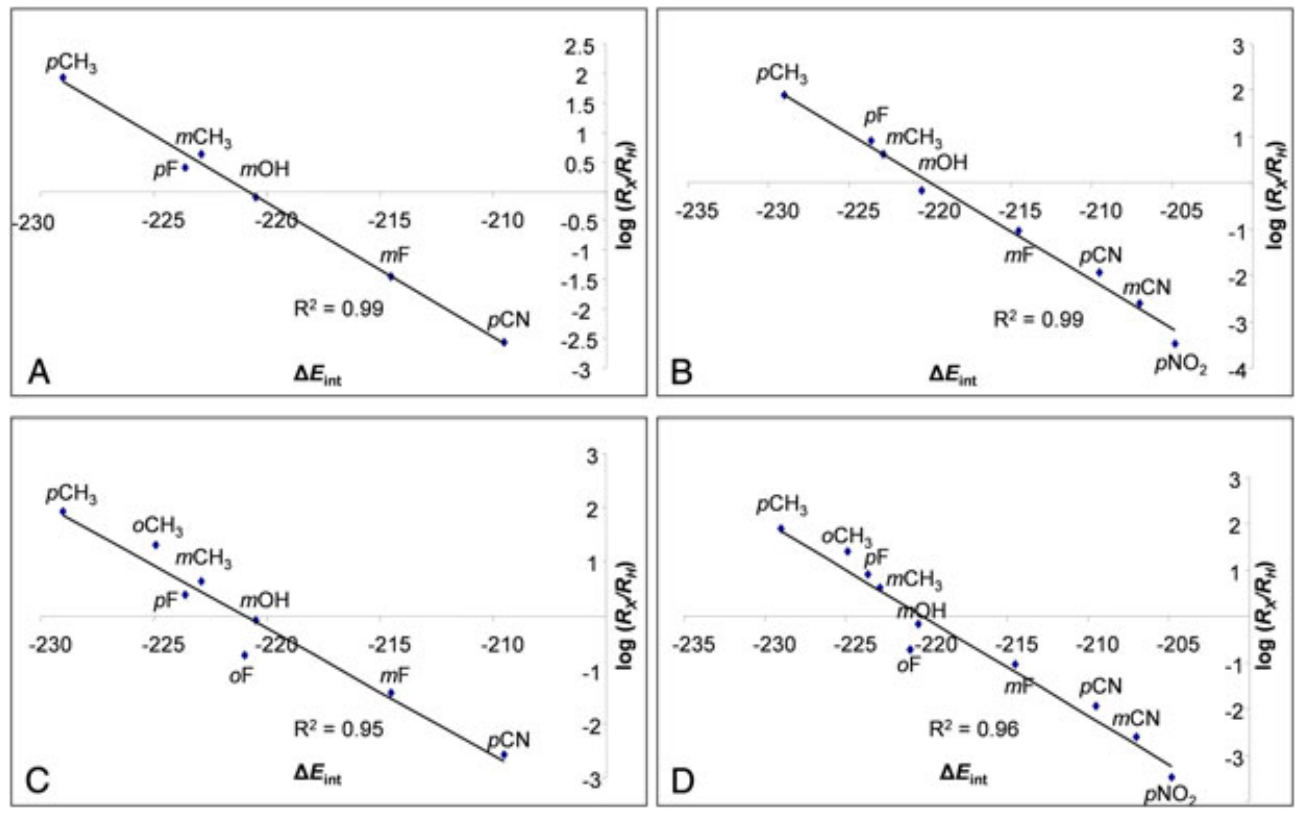

Figure 4. Plot of $\log \left(R_{\mathrm{X}} / R_{\mathrm{H}}\right)$ determined from CID product ion spectra of doubly and triply protonated, $\left[\mathrm{MH}_{\mathrm{n}}\right]^{\mathrm{n}+}(\mathrm{n}=2$ or 3$)$, peptide IGK $\mathrm{X}$ GVAR (where $\mathrm{K}_{\mathrm{X}}$ represents a substituted benzylamine-derivatized lysyl residue) versus the calculated interaction energies ${ }^{[20]}\left(\Delta E_{\text {int }}\right)$ between the ${ }^{+} \mathrm{CH}_{2}$ and $\mathrm{C}_{6} \mathrm{H}_{4} \mathrm{X}$ components of the dissociated $\mathrm{X}$-substituted benzylic carbocations: (A) $m$-X-and $p$-X-substituted $\left[\mathrm{MH}_{2}\right]^{2+}$ precursors; (B) $m$-X- and $p$-X-substituted $\left[\mathrm{MH}_{3}\right]^{3+}$ precursors; (C) $o-\mathrm{X}-, m-\mathrm{X}-$, and $p$-X-substituted $\left[\mathrm{MH}_{2}\right]^{2+}$ precursors; (D) $o-\mathrm{X}-, m-\mathrm{X}-$, and $p-\mathrm{X}$-substituted $\left[\mathrm{MH}_{3}\right]^{3+}$ precursors. Note: $R_{X}$ represents the sum of the CCE product ion intensities of an $\mathrm{X}$ substituted derivative over the sum of the remainder of the product ion intensities. $R_{\mathrm{H}}$ represents the corresponding ratio of the unsubstituted derivative.

mechanism releasing the benzyl moiety as a neutral species (manuscript in preparation). retro-Michael cleavage was not observed for $m$-OH or $p$-OH derivatives.

\section{DISCUSSION}

Presented here is a demonstration of the substituent effect for the manipulation of the ratio of product ion intensities originating from CCE dissociation of benzylamine-derivatized peptides. It was shown that Hammett substituent constants can be applied effectively for predicting the relative influence of various substituents on the relative formation of CCE products. It was also shown that the relative abundance of CCE product formation is directly related to the substituent influence on the relative $\Delta E_{\text {int }}$ of the benzylic carbocation product and not on the substituent influence on the gas-phase PA of $\mathrm{N}_{\varepsilon}$. A stronger correlation between the relative product ion intensity ratios and $\Delta E_{\text {int }}$ was observed compared to the Hammett substituent constants and $\Delta E_{\text {int }}$ may be applicable to some ortho substituents.

Other benzylamine-derivatized peptides likely exhibit different propensities for producing CCE reaction products. Considering the complex mixtures of peptides encountered in proteome analysis, countless factors can contribute to this, including amino acid composition and sequence, size, charge, and post-translational modifications, to name just a few. However, for each respective peptide, the relative influences of substituents with distinct electronic properties upon the relative abundance of CCE products formed would in general be similar to that observed here for IGK ${ }_{X}$ GVAR. For example,
Supplementary Fig. S2 (Supporting Information) displays a plot of $\log \left(R_{\mathrm{X}} / R_{\mathrm{H}}\right)$ versus $\sigma$ for the doubly charged precursor of the peptide $\mathrm{HAK}_{X} \mathrm{LGR}$ (derivatized with the selected analogs $m-\mathrm{CH}_{3}, p-\mathrm{CH}_{3}, m-\mathrm{OH}, m-\mathrm{F}$, and $\left.p-\mathrm{F}\right)$. The ratios correlate well with $\sigma$ for this peptide as well. Unlike triply charged IGK ${ }_{X}$ GVAR derivatives, which exhibit an intense $\mathrm{y}_{6}{ }^{2+}$ product ion peak, triply charged $\mathrm{HAK}_{x} \mathrm{LGR}$ derivatives exhibit no evidence for products formed via the $b_{m}-y_{n}$ pathway except for those having substituents with very high Hammett constants. As stated above, IGK $\mathrm{X}$ GVAR is unique compared to most peptides that we have examined as most dissociate almost exclusively via the CCE pathway when in the triply charged state.

This work also provides valuable insight toward our continuing goal for designing benzyl derivatives which induce selective CCE reactivity regardless of the precursor ion charge state. Substituents with Hammett constants near or below -0.20 are effective at promoting such selectivity. For example, the CID product ion spectrum of the $p-\mathrm{CH}_{3}$ derivative (Fig. $3(\mathrm{C})$ ) could be a suitable template for designing cross-linking reagents that induce selective side-chain cleavage of cross-linked peptides because selective side-chain cleavage is desired and para-alkylation is essential for varying the lengths of cross-linking reagents. The availability of an extensive catalogue of Hammett substituent constants, as well as the limited availability of $\Delta E_{\text {int }}$ values, allows for the strategic selection and incorporation of substituents onto the core benzylamine structure for manipulating product ion intensity ratios as desired. Furthermore, an estimation of $\Delta E_{\text {int }}$ for undetermined substituted benzylic carbocations can be obtained due to the strong correlation between $\Delta E_{\text {int }}$ 
and the Hammett substituent constant. ${ }^{[20]}$ This provides flexibility for the development of reagents for protein cross-linking, stable-isotope quantification tags, and other applications. Additionally, substituents which provide complimentary properties like solubility enhancement and/or selective enrichment could be incorporated.

\section{SUPPORTING INFORMATION}

Additional supporting information may be found in the online version of this article.

\section{Acknowledgements}

This research was supported by the NCRR (P41 RR018627) to P.C.A. We would also like to thank the Charles Brooks research group in the University of Michigan Chemistry Department for access to their computer cluster.

\section{REFERENCES}

[1] D. F. Hunt, J. R. Yates, J. Shabanowitz, S. Winston, C. R. Hauer. Protein sequencing by tandem mass spectrometry. Proc. Natl. Acad. Sci. USA 1986, 83, 6233.

[2] D. N. Perkins, D. J. C. Pappin, D. M. Creasy, J. M. Cottrell. Probability-based protein identification by searching sequence databases using mass spectrometry data. Electrophoresis 1999, $20,3551$.

[3] J. K. Eng, A. L. McCormack, J. R. Yates III. An approach to correlate tandem mass spectral data of peptides with amino acid sequences in a protein database. J. Am. Soc. Mass Spectrom. 1994, 5, 976.

[4] D. Fenyö, R. C. Beavis. A method for assessing the statistical significance of mass spectrometry-based protein identifications using general scoring schemes. Anal. Chem. 2003, 75, 768.

[5] P. A. C. Diego, B. Bajrami, H. Jiang, Y. Shi, J. A. Gascon, X. Yao. Site-preferential dissociation of peptides with active chemical modification for improving fragment ion detection. Anal. Chem. 2010, 82, 23.

[6] Y. Lu, M. Tanasova, B. Borhan, G. E. Reid. Ionic reagent for controlling the gas-phase fragmentation reactions of crosslinked peptides. Anal. Chem. 2008, 80, 9279.

[7] F. Dreiocker, M. Q. Müller, A. Sinz, M. Schäfer. Collisioninduced dissociative chemical cross-linking reagent for protein structure characterization: applied Edman chemistry in the gas phase. J. Mass Spectrom. 2010, 45, 178.

[8] E. S. Simon, P. G. Papoulias, P. C. Andrews. Gas-phase fragmentation characteristics of benzyl-aminated lysyl-containing tryptic peptides. J. Am. Soc. Mass Spectrom. 2010, 21, 1624.
[9] V. D. Knyazev, S. E. Stein. Classical trajectories and RRKM modeling of collisional excitation and dissociation of benzylammonium and tert-butyl benzylammonium ions in a quadrupole-hexapole-quadrupole tandem mass spectrometer. J. Am. Soc. Mass Spectrom. 2010, 21, 425.

[10] A. R. Katritzky, C. H. Watson, Z. Dega-Szafran, J. R. Eyler. Collisionally activated dissociation of $\mathrm{N}$-alkylpyridinium cations to pyridine and alkyl cations in the gas phase. J. Am. Chem. Soc. 1990, 112, 2471.

[11] V. Gabelica, E. De Pauw. Internal energy and fragmentation of ions produced in electrospray sources. Mass Spectrom. Rev. 2005, 24, 566.

[12] L. P. Hammett. Some relations between reaction rates and equilibrium constants. Chem. Rev. 1935, 17, 125.

[13] C. Hansch, A. Leo, R. W. Taft. A survey of Hammett substituent constants and resonance and field parameters. Chem. Rev. 1991, 91, 165.

[14] M. J. Frisch, G. W. Trucks, H. B. Schlegel, G. E. Scuseria, M. A. Robb, J. R. Cheeseman, J. A. Montgomery, T. Vreven, K. N. Kudin, J. C. Burant, J. M. Millam, S. S. Iyengar, J. Tomasi, V. Barone, B. Mennucci, M. Cossi, G. Scalmani, N. Rega, G. A. Petersson, H. Nakatsuji, M. Hada, M. Ehara, K. Toyota, R. Fukuda, J. Hasegawa, M. Ishida, T. Nakajima, Y. Honda, O. Kitao, H. Nakai, M. Klene, X. Li, J. E. Knox, H. P. Hratchian, J. B. Cross, V. Bakken, C. Adamo, J. Jaramillo, R. Gomperts, R. E. Stratmann, O. Yazyev, A. J. Austin, R. Cammi, C. Pomelli, J. W. Ochterski, P. Y. Ayala, K. Morokuma, G. A. Voth, P. Salvador, J. J. Dannenberg, V. G. Zakrzewski, S. Dapprich, A. D. Daniels, M. C. Strain, O. Farkas, D. K. Malick, A. D. Rabuck, K. Raghavachari, J. B. Foresman, J. V. Ortiz, Q. Cui, A. G. Baboul, S. Clifford, J. Cioslowski, B. B. Stefanov, G. Liu, A. Liashenko, P. Piskorz, I. Komaromi, R. L. Martin, D. J. Fox, T. Keith, M. A. Al-Laham, C. Y. Peng, A. Nanayakkara, M. Challacombe, P. M. W. Gill, B. Johnson, W. Chen, M. W. Wong, C. Gonzalez, J. A. Pople. Gaussian 03, Revision C.02, Gaussian, Inc., Wallingford, CT, 2004.

[15] I. P. Csonka, B. Paizs, G. Lendvay, S. Suhai. Proton mobility and main fragmentation pathways of protonated lysylglycine. Rapid Commun. Mass Spectrom. 2001, 15, 1457.

[16] B. Paizs, S. Suhai. Fragmentation pathways of protonated peptides. Mass Spectrom. Rev. 2005, 24, 508.

[17] J. V. Olsen, B. Macek, O. Lange, A. Makarov, S. Horning, M. Mann. Higher-energy C-trap dissociation for peptide modification analysis. Nat. Methods 2007, 4, 709.

[18] L. P. Hammett. The effect of structure upon the reactions of organic compounds. Benzene derivatives. J. Am. Chem. Soc. 1937, 59, 96.

[19] T. Ziegler, A. Rauk. On the calculation of bonding energies by the Hartree Fock Slater method. Theor. Chim. Acta 1977, 46, 1.

[20] I. Fernández, G. Frenking. Correlation between Hammett substituent constants and directly calculated $\pi$-conjugation strength. J. Org. Chem. 2006, 71, 2251.

[21] M. Charton. The application of the Hammett equation to ortho-substituted benzene reaction series. Can. I. Chem. 1960, 38, 2493 